\title{
CAN A LEARNING ANALYTICS DASHBOARD PARTICIPATIVE DESIGN APPROACH BE TRANSPOSED TO AN ONLINE-ONLY CONTEXT?
}

\author{
Katia Oliver-Quelennec ${ }^{1,2,3}$, François Bouchet ${ }^{1}$, Thibault Carron ${ }^{1}$ and Claire Pinçon ${ }^{2}$ \\ ${ }^{1}$ Sorbonne Université, CNRS, LIP6, F-75005 Paris, France \\ ${ }^{2}$ Univ. Lille, CHU Lille, ULR 2694, METRICS: Évaluation des Technologies de Santé et des Pratiques Médicales, \\ F-59000 Lille, France \\ ${ }^{3}$ Univ. Lille, GIVRE, DIP, France
}

\begin{abstract}
In-person sessions of participative design are commonly used in the field of Learning Analytics, but to reach students not always available on-site (e.g. during a pandemic), they have to be adapted to online-only context. Card-based tools are a common co-design method to collect users' needs, but this tangible format limits data collection and usage. We propose here two steps: first to use an existing co-design card deck-based method for our university context and next to adapt this new method called PADDLE (PArticipative Design of Dashboard for Learning in Education) for an online use.

This article presents key factors and points of attention identified in adapting a card-based co-design method into a digital version for designing learning dashboards. This digital adaptation and the associated tool, ePADDLE, were tested with first year university students divided into 18 groups $(\mathrm{N}=58)$. All groups have successfully designed a dashboard, and using the original evaluation scales, users have evaluated ePADDLE as almost as suitable as the original method. Thanks to the traces provided by the online version, we rely on speech acts to identify favorable conditions for successful collaboration.
\end{abstract}

\section{KEYWORDS}

Learning Analytics Dashboard, Co-Design, Participatory Design, Cards

\section{INTRODUCTION}

Faced with the massification of higher education, traditional teaching is not always suitable for training an increasingly larger and more heterogeneous student audience. One of the solutions to answer this development is the use of digital technology for (1) training and (2) personalization of training based on the collection of learning data and on their analysis (learning analytics). The dashboard, a classic decision-making aid tool, can support learning and is developing constantly in the field of Technology Enhanced Learning (TEL), mainly for teachers and students (Bodily et al., 2017). The problem remains to be able to provide appropriate Learning Analytics Dashboard (LAD) to this heterogeneous public, meeting their needs.

In the field of human-machine interface, but also more broadly, user-centered design is a design philosophy which aims at really satisfying users' self-expressed needs (Sanders, 2002). Concerning the conception of LAD, several research studies have shown the importance of explaining clearly the pedagogical objectives (Ifenthaler et al., 2005) and of choosing a relevant method (Jivet et al., 2017). To build LADs, participatory design (Ruiz et al., 2018) is a method adapted and often already developed in the design of TEL. However, according to (Prieto Alvarez et al., 2020), students are often absent in the participatory design of TEL, which could explain why some LADs are not always adapted to the learning target. Our first goal was thus to rely on such an existing co-design method for a higher education student context.

Moreover, co-design sessions usually involve an in-person session with participants sitting around a table, which is challenging when social distancing is mandatory, or simply when it is hard to schedule a moment for all stakeholders to be available in a given location. There are reasons to question whether an online version with remote participants would be as efficient, as virtual collaboration can act as a brake on the success of the collaboration by limiting exchanges through text and voice, without facial expressions or body language. (McNair et al., 2010) identified the importance for participants to establish a sense of trust, which can be 
challenging to establish online. Therefore, our second goal is to verify whether an online co-design approach of dashboard for and by students can lead to successful results by adapting an existing method to an online context assisting in trace recovery. These traces are made of (1) observation data of the use of the method to facilitate its evolution, (2) intermediate data to be able to understand the conditions of effective collaboration, and (3) production results. Finally, we will present the data collected and the results of several experiments showing that this approach might indeed be an efficient replacement for face-to-face sessions. We also explore the new possibilities that the traces provide in order to assess the quality of the interactions and outcomes.

The remainder of this paper is organized as follows. In the next section, we start by presenting previous works on participatory design leading to the conception of LAD, then we present the face-to-face method we chose to adapt, called PADDLE, and our proposal for a digital version, before describing the experiments carried out and the data collected. Next, we present our results before concluding with a discussion about the pros and cons of this digital transposition and by presenting the perspectives opened by this work.

\section{PREVIOUS WORK}

\subsection{Participatory Design}

Work by Schneider et al. (2011) has shown that the use of tangible objects (such as cards) can facilitate collaboration and could explain the recurrent use of this format for co-design. However, other works focused on collaboration have also shown that the use of digital technology engages participants in productive processes and in a co-construction framework (Jeong et al., 2016). It is therefore unclear a priori how a digital adaptation of an existing tangible co-design approach will be perceived. On the one hand, the tool can compel users to guide them and help them stay focused on their main task, but on the other hand, it can also limit creativity if it is too direct. Thus, there is a need to find the right balance in its design.

With participatory design, "the user becomes a critical component of the process" (Sanders, 2002), and they can be involved using the appropriate tools, such as card decks (Roy et al., 2019). For learning analytics applications, some card decks-based approaches such as LA-DECK (Prieto Alvarez et al., 2020) have led to successful outcomes in terms of design: "the cards succeeded in playing very similar roles to those documented in the literature on successful card-based design tools". But LA-DECK focuses more on establishing a dialogue between designers, data scientists and users than purely on letting users express their needs.

A literature review of 155 card-based design tools (Roy et al., 2019) shows that this format is widely used: their tangible form combines several ideas, with a limited amount of information, thus providing a good intermediary between structureless tools (post-it) and complete tools (instruction manual). However, this review also points out that only "some of the tools are [...] also available as apps or online." Moreover, the existence of a digital version does not guarantee that traces are recorded, as most methods are more interested in final production than in an analysis of the processes used to obtain them. Finally, when the information was explicitly provided by the authors, it appears that none of these tools was used with remote participants: everyone was always in a face-to-face context around a table. These sessions are often accompanied by a facilitator who introduces the session, presents the cards, answers any questions and concludes the session (Prieto Alvarez et al., 2020). Some studies about co-design (Goldman et al., 2019) uses both online activities and face-to-face time, but as far as we know, none were in online-only context, nor study how to adapt from face-to-face to the full distance.

\subsection{Learning Analytics Dashboard}

Although the research field around learning analytics dashboards (LAD) is quite young (Schwendimann et al., 2017), there are several reviews of the literature on the LADs already developed (Verbert et al., 2014). LADs allow the learners to be aware of their progress, to create meaning and to take decisions that will impact their learning. But Jivet et al. (2017) explains that LADs are not always developed in line with clear educational objectives, and that making people aware of their journey is not enough to improve learning. In addition, LADs can also cause negative effects (Tan et al., 2017; Teasley et al., 2017), in particular when they provide comparisons with peers for certain student profiles. It is therefore necessary to create LADs adapted to the 
learning contexts and according to the students' needs. Some works show students' expectations for personalization and the importance of having an adaptable LAD (Roberts et al., 2017; Teasley et al., 2017). There are also early works on the design of adaptive LADs, such as those of Dabbebi et al. (2019) on the design and the dynamic generation of contextual LADs for teachers. All these studies highlight the interest of adaptive LADs but have not been developed for the learners themselves.

To build LADs, participatory design (Ruiz et al., 2018) is a method adapted and often already developed in the design of TEL. As seen before and in the previous works (Lucero et al., 2016; Ruiz et al., 2018; Roy et al., 2019), this approach is generally implemented using cards. The participatory design kit developed by Dabbebi et al. (2019) offers a complete method for designing LADs, the first uses of which were carried out with secondary school teachers. Therefore, it appeared to be the closest to our goals, and we chose to propose an adaptation of this method to students in the context of higher education.

\section{THE PADDLE METHOD}

To design Learning Analytics Dashboards (LAD), Dabbebi et al. (2019) developed a participatory-based design tool also using card decks which was positively rated by its users. Our adaptation of this method to the context of higher education and focused on co-design by students is called PADDLE (PArticipative Design of Dashboard for Learning in Education). We used an iterative approach to test and propose adaptations of the design kit for our student target. First of all, we practiced with the existing tool by working with its intended audience (teachers) over two sessions, but in a higher education context. This appropriation time have enabled us to confirm the interest of the method in another university context and allowed us to confirm the method was suitable to easily collect users' needs, and that it received positive feedback from participants. We were thus able to define a first variation. The adaptation of this method for higher education includes changes in vocabulary, length of time for the student target and the addition of questions for participants. Vocabulary related to secondary education such as "pupil, class, school, department, academy" has been changed to "student, promotion, institution, regional, national". The second variation was necessary to adapt the tool to students. In order to more easily fit in time slots usually available to them between two classes, we reduced the duration of a session from 150 minutes to 90 minutes, which led to adopting a question-based approach to better guide them and thus save time. For example, the card entitled "Monitoring" initially described by a definition, has been replaced by "How do you keep track of your work? What do you need to track your work?". The participants take turns answering the questions and thus identify their possible needs. Naturally, these adaptations do not prevent from using PADDLE with the initial targets (teachers).

PADDLE allows to co-design LADs in small groups of two to five people. The sessions last from 90 minutes (for students) to 120 minutes (for teachers) and consist of five phases: (1) introduction, (2) choice of the LAD goal, (3) definition of the context, (4) choosing the data to track, the indicators to compute and the associated visualizations to display them, and (5) drawing of the LAD to show how all the visualizations can be associated together in an integrated dashboard.

\subsection{Material}

The session is supervised by a facilitator who supports debates and helps participants in formalizing their ideas. Nonetheless, the facilitator intervenes only on request or when he/she detects a group is struggling, in order to give participants autonomy. In particular they refrain from giving examples of indicators in a learning context or to express judgment on participants' proposals, in order not to inhibit nor direct the students' discussions. To facilitate transport, pooling and animation, the board has been transformed into convenient cards: PADDLE comes in the form of laminated cards to be able to reuse them and magnetic cards to manipulate them on a whiteboard (cf. Figure 1). Participants must set a goal and then complete a board to describe their context before identifying the relevant data and their graphic representations. Finally, they assemble these elements to design their LAD.

Traces of the sessions are collected using audio recordings of the groups, photos of intermediate stage results, photos of the LAD produced and a paper-based or online evaluation questionnaire. 


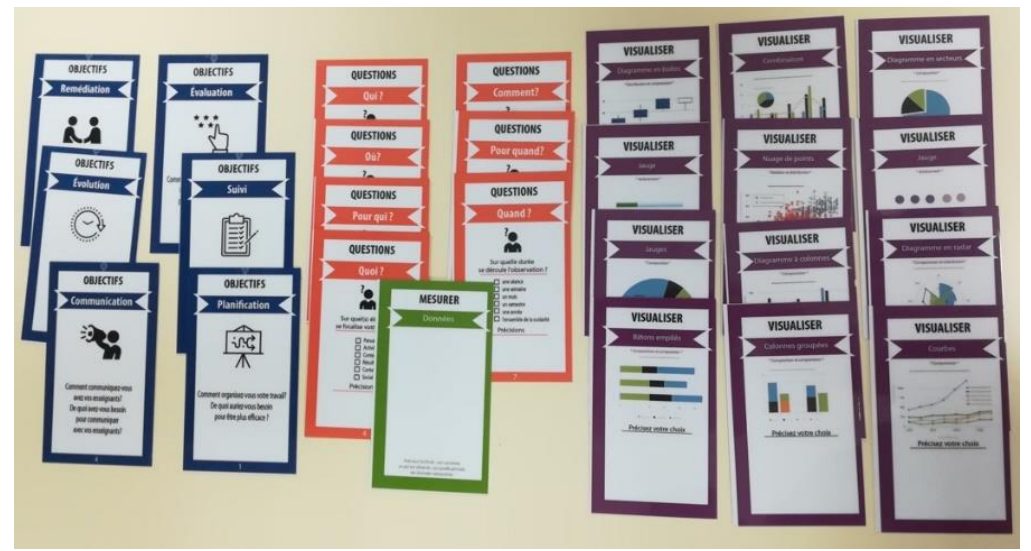

Figure 1. PADDLE Cards

\subsection{Method \& Data Collected}

We carried out with volunteer students three recorded PADDLE sessions followed by a qualitative analysis: (1) two of them with two pairs of $1^{\text {st }}$ year language students enrolled in a training formation dedicated to mastering the university environment, and (2) one with three $5^{\text {th }}$ year pharmacy students in the context of a course using a serious game based on professional simulation. For each session, we recorded the interactions between students, we listed the cards selected, the data they chose to display on their LAD, the final display of the LAD they defined and we asked participants to complete the original evaluation questionnaire (Dabbebi et al., 2019). This evaluation consists in 7 statements to rate using 5-point Likert scale to evaluate their satisfaction both with the process and its outcome (the dashboard they designed). Results are presented in section 5 . This data collection was led after declaring it to the university data protection officer (DPO).

As explained in introduction, it could be more convenient to use such a method in remote sessions using online tools, but questions remains open regarding the impact it may have on the quality of the collaboration.

\section{REMOTE CO-DESIGN WITH EPADDLE}

Scheduling co-design sessions can be difficult, and even impossible in a global pandemic context. Moreover, even when in-person sessions can happen, it is harder to collect traces of activity when tangible objects are manipulated. This led us to propose to transform the PADDLE method and cards deck into the application ePADDLE (cf. Figure 2); a digital format of PADDLE improving the traces collection.

PADDLE

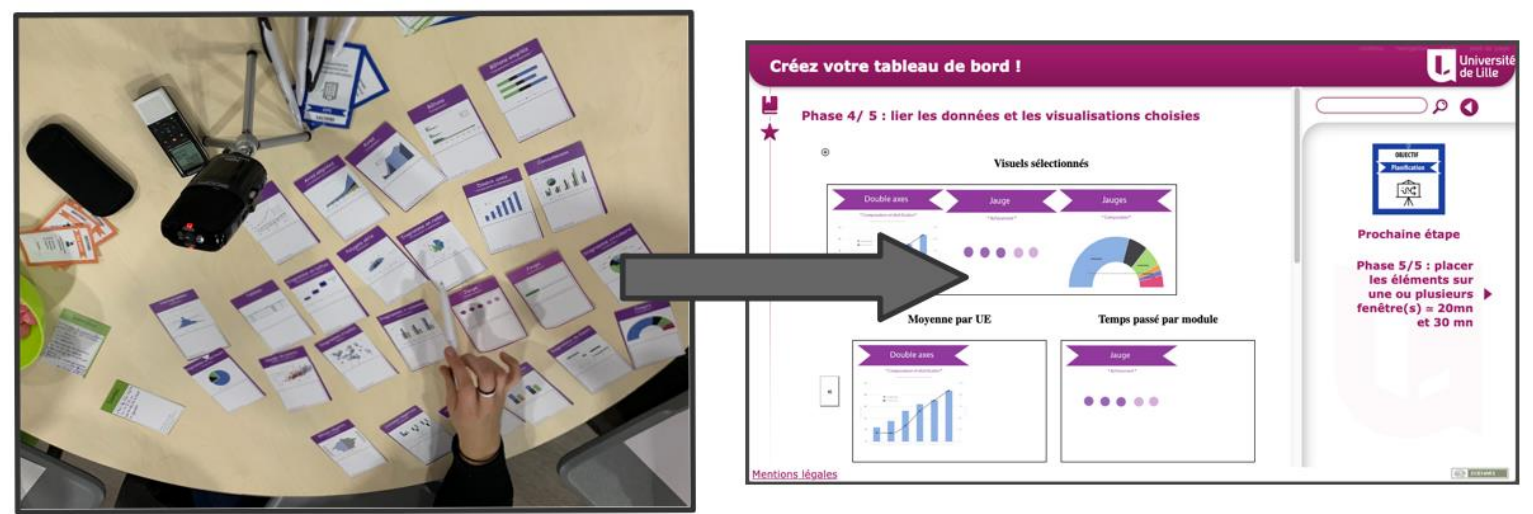

Figure 2. From PADDLE with tangible cards to ePADDLE for remote online co-design sessions 


\subsection{The ePADDLE Method}

\subsubsection{Material}

The ePADDLE application keeps PADDLE's key elements: (1) its original 5 phases (presentation, decision choice, context, data and visualisation choice and LAD design), (2) the number of participants (2 to 4 in each group), (3) the facilitator whose role is mostly to introduce the goals of the workshop at first, and then to answer to both technical questions and methodological questions. Among the new elements we had to adapt or introduce to organize a remote online session, we can mention: (1) the fact that groups are asked to work together with a web conferencing tool where they can chat, talk by voice and share their screens, (2) two additional specific roles to take into account that it is harder for the session facilitator to keep track of the progression of each group compared with a session where all groups are in the same room: the scribe (whose role is to connect to the ePADDLE app, share their screen and take note of answers from the group), and the time keeper (whose role is to ensure some groups do not spend too much time on some phases), (3) the fact that activities are tracked using the LMS Moodle, commonly used in higher education, as the ePADDLE module is open source and can be embedded into the Moodle ${ }^{1}$.

\subsubsection{Method \& Data Collected}

To validate the claim that ePADDLE supports LAD co-design, 4 sessions using ePADDLE were organized, involving overall $\mathrm{N}=58$ first year university students in multimedia design, randomly assigned to 18 groups of 2 to 4 students. During two sessions, there was one facilitator for each group whereas the two other sessions involved only one facilitator who was virtually moving from one group to another.

The audio interactions of each group were recorded. Each participant was asked to fill the same post-session questionnaire used with PADDLE. We also asked participants to fill Belbin team roles questionnaire (Belbin, 2010), to be able to evaluate further on whether the types of roles impacted the quality of the interactions and of the outcome, and asked them to rate how well they knew the other participants in their groups. The Belbin user profiles will be confronted to use of recurrent speech acts patterns in the records (e.g. Question (1) - Answer (1-N) - Acknowledgement of contribution (1-N) or Command - Announcement or again Correct - Accountability) in order to evaluate the collaboration quality. We also proposed a poll to the participants allowing them to vote for the best LAD. In this paper, we focus only on the transposition process of properties identified to enhance trace collection from a face-to-face method to a remote one.

\subsection{Transposition of Relevant Properties of PADDLE}

We identified 8 properties in the PADDLE method (cf. Table 1) and considered their possible digital transpositions to improve trace collection. These 8 properties were chosen to be generic enough to assume that they would also be relevant for any other adaptation of a card-based co-design method into an online remote version, as none are intrinsically related to mechanics exclusive to PADDLE. We believe however that the way we chose to translate them are not unique, and it is possible that for other methods, other translations would be more relevant than the ones chosen here.

Table 1. Translating the different properties of PADDLE into ePADDLE

\begin{tabular}{|c|c|c|c|}
\hline Properties & PADDLE & ePADDLE & Additional traces \\
\hline Initial explanations & $\begin{array}{l}\text { Slideshow presented by the } \\
\text { facilitator }\end{array}$ & Slideshow presented by the facilitator & - \\
\hline $\begin{array}{l}\text { Collaboration } \\
\text { between participants }\end{array}$ & $\begin{array}{l}\text { Card selection and card } \\
\text { annotations by participants }\end{array}$ & $\begin{array}{l}\text { Participating with scribe role and } \\
\text { fields to be filled either individually } \\
\text { or collectively }\end{array}$ & $\begin{array}{l}\text { Individual and group } \\
\text { responses from } \\
\text { participants }\end{array}$ \\
\hline $\begin{array}{l}\text { Scripting } \\
\text { collaboration }\end{array}$ & $\begin{array}{l}\text { Ordered cards and regular } \\
\text { interventions by the facilitator }\end{array}$ & $\begin{array}{l}\text { Online interface for scripted } \\
\text { collaboration }\end{array}$ & Time spent by phase \\
\hline $\begin{array}{l}\text { Answers to } \\
\text { questions }\end{array}$ & Session facilitator role & $\begin{array}{l}\text { Group facilitator or facilitator for the } \\
\text { session }\end{array}$ & $\begin{array}{l}\text { Trace questions in the } \\
\text { chat }\end{array}$ \\
\hline
\end{tabular}

\footnotetext{
${ }^{1}$ https://padlad.github.io/productions
} 


\begin{tabular}{|c|c|c|c|}
\hline $\begin{array}{l}\text { Time regulation of } \\
\text { the session }\end{array}$ & Session facilitator role & $\begin{array}{l}\text { Participating with time master role } \\
\text { and follow-up of the session } \\
\text { facilitator }\end{array}$ & - \\
\hline $\begin{array}{l}\text { Visibility of } \\
\text { previous decisions }\end{array}$ & $\begin{array}{l}\text { Magnetic cards on the } \\
\text { whiteboard and annotation of } \\
\text { participants }\end{array}$ & $\begin{array}{l}\text { Summary of the choices made } \\
\text { between each phase and via the menu } \\
\text { of the digital device }\end{array}$ & $\begin{array}{l}\text { Summary of previous } \\
\text { choices and number of } \\
\text { times the summary was } \\
\text { viewed }\end{array}$ \\
\hline $\begin{array}{l}\text { Graphical production } \\
\text { of the result }\end{array}$ & $\begin{array}{l}\text { Stationery/Office materials } \\
\text { (paper, pencil, scotch, ...) }\end{array}$ & $\begin{array}{l}\text { Tool of choice: paper, participant- } \\
\text { controlled software or online editing } \\
\text { software }\end{array}$ & Link if online production \\
\hline $\begin{array}{l}\text { Method for results } \\
\text { assessment }\end{array}$ & Questionnaire & $\begin{array}{l}\text { Questionnaire with link in the digital } \\
\text { device and Belbin profile test for } \\
\text { collaboration evaluation }\end{array}$ & - \\
\hline
\end{tabular}

More precisely, here are the justifications of our choices; we tried not to lose their primary functionality. The first three properties are only associated to one of the five phases:

- Initial explanations (phase 1): the use of a video makes it easier to collect traces (time spent listening to the video, number of views), but the absence of a human to initiate the activity could be detrimental to the motivation of the group. So, we chose to keep a human briefing.

- Graphic production (phase 5): using digital tools can have potentially more readable results than a handwritten production. In the case of online software use, the link to the productions is saved.

- Evaluation of the method and the results obtained (phase 5): the evaluation method initially developed by questionnaire is adapted to the digital format to facilitate the analysis.

The five following properties are more global and associate to the method overall:

- Collaboration between participants: one option considered consisted in adding RFID chips to identify manipulated cards, to keep the tangible aspect of PADDLE, but it limits the possibility of remote sessions. So, we preferred to force each member of a group to give their opinion by proposing individual fields for some questions. This approach requires all members of the group to participate, reinforcing the commitment in the production process and allowing to collect each participants' traces.

- Scripting collaboration: scripting the digital device reproduces the order of the cards originally proposed and blocks the possibility of inadvertently mixing the cards. The digital format allows collecting information on the time spent on each card, thus allowing to identify for instance the most discussed cards.

- Answers to participants' questions: a chatbot could be considered in order to deal with simple questions, to more easily trace recurring problems as well as guarantee that the provided responses are standardized. However, chatbots can tend to distract participants (who can spend time gaming the system instead of accomplishing the task at hand (Bouchet, 2009)), lead to distrust in the whole approach if the answers are not appropriate, or may over-guide participants in the method. For these reasons, we chose for now to force participants to call the facilitator, even if it may slow down the process.

- Regulation of the session: time regulation is possible to force the transition from one phase to another but may limit rich exchanges, and it is recommended that participants be involved in the regulation of their collaborative activities (McNair et al., 2010). The digital format allows to trace the time spent in each phase.

- Visibility of previous decisions: posting a summary of each phase allows the group to check their choices and change their minds. Access to this screen can be traced to estimate the coordination of decisions with past choices.

\section{RESULTS OF THE EXPERIMENTS}

Each PADDLE property implementation has either been retained as they originally were, or transposed through an implementation that allows for better tracing. The ePADDLE sessions made it possible to successfully design 18 LADs (one per group - cf. Figure 3), as no group failed to propose a dashboard at the end of the session. Moreover, it allowed to easily collect the data captured during the session, in addition to the traces usually collected with PADDLE. The follow-up of the questions was successfully managed with only one 
facilitator per session. The regulation can be considered adapted because the duration of the workshops remained mostly in the expected time (from 63 to $115 \mathrm{~min}, \mathrm{M}$ - $92 \mathrm{~min}, \mathrm{SD}-18 \mathrm{~min}$ ). Finally, the visibility of previous decisions and graphic production can be validated by the productions made, which are in line with the choices of the participants.

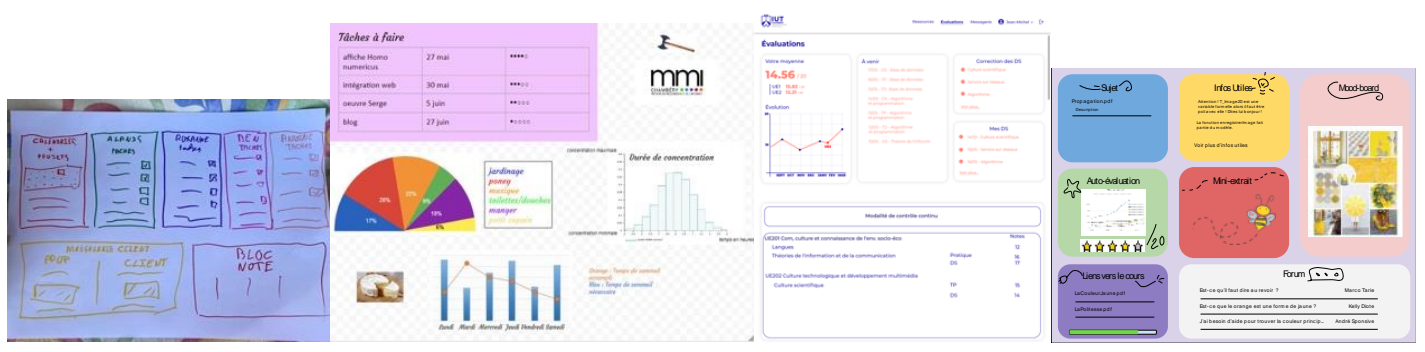

Figure 3. Examples of LAD designed with PADDLE and ePADDLE

However, by reusing the original evaluation questionnaire (Dabbebi et al., 2019), according to user evaluation (see Table 2), ePADDLE was rated a bit lower than PADDLE used in in-person sessions, significantly so regarding help to creativity where the tool could not compete with a real paper whiteboard.

Naturally, these results have to be confirmed with larger samples.

Table 2. PADDLE and ePADDLE user opinions

\begin{tabular}{lllll}
\hline Properties & Statements to rate using 5-point Likert scale & PADDLE (N=8) & ePADDLE (N=58) & $\mathrm{p}^{*}$ \\
\hline Collaboration & $\begin{array}{l}\text { The tool helped you to have a good group } \\
\text { dynamic. }\end{array}$ & $\mathrm{M}=4.57, \mathrm{SD}=0.79$ & $\mathrm{M}=4.14, \mathrm{SD}=0.98$ & 0.14 \\
& $\begin{array}{l}\text { The tool helped you to converge towards a } \\
\text { solution. }\end{array}$ & $\mathrm{M}=4.29, \mathrm{SD}=0.76$ & $\mathrm{M}=4.14, \mathrm{SD}=0.87$ & 0.27 \\
Scripting & $\begin{array}{l}\text { The tool is easy to handle. } \\
\text { Cards are easily understandable. }\end{array}$ & $\mathrm{M}=4.63, \mathrm{SD}=0.74$ & $\mathrm{M}=4.17, \mathrm{SD}=0.75$ & 0.15 \\
& $\begin{array}{l}\text { The tool has enabled you to better specify your } \\
\text { needs. }\end{array}$ & $\mathrm{M}=4.63, \mathrm{SD}=0.52$ & $\mathrm{M}=3.64, \mathrm{SD}=1$ & 0.09 \\
& $\begin{array}{l}\text { The tool has enabled you to find original } \\
\text { solutions. }\end{array}$ & $\mathrm{M}=4.75, \mathrm{SD}=0.46$ & $\mathrm{M}=3.69, \mathrm{SD}=0.98$ & 0.005 \\
& $\begin{array}{l}\text { And this solution seems relevant to you. } \\
\text { And }\end{array}$ & $\mathrm{M}=4.71, \mathrm{SD}=0.49$ & $\mathrm{M}=3.97, \mathrm{SD}=0.90$ & 0.01 \\
\hline
\end{tabular}

* The degree of significance of the Mann-Whitney test after Bonferroni correction

\section{CONCLUSION AND PERSPECTIVES}

Our results with students are encouraging and show the possibility of developing online co-design sessions, and achieve our main goal, co-designing LADs. Indeed, if the main advantage of this digital transposition is to obtain pre-formatted data that allows a rapid processing of these, we can see other benefits, such as remote use. Moreover, this transposition has led to enrichment to the initial method, such as the definition of multiple roles originally all under the responsibility of the session facilitator. However, there are still limits on which this transposition can evolve, such as embedding a graphic production tool which would not only facilitate this activity for participants and standardize the dashboard produced by different group, but also help in collecting traces still poor for this phase (only the final dashboard is collected but not the design process of this dashboard). Another limit relies on the validity of the properties in another context: although chosen to be generic, only transpositions of the same properties in other contexts would confirm it.

The next stages of work will focus on improving the quality of group dynamics, an important point to enable remote collaborative work and fully validate this tool. This initial work should be further developed by testing ePADDLE in other contexts (using different target group, considering the impact of how participants are recruited) and by comparing with adaptations of other co-design methods. These additional studies will help to determine rules to follow for such transpositions to be successful. Future work will also focus on using 
post-session questionnaires to understand group dynamics and identify potential favourable conditions for successful collaboration through (1) an analysis of speech acts based on (McNair et al., 2010), and (2) finding links with Belbin's collaboration profile. Such analyses could help in enhancing initial group formation or during a session to identify clues indicating a less productive collaboration.

\section{ACKNOWLEDGEMENT}

This work is included in the P3 project, developed by Université de Lille and co-financed by the iSite Université Lille Nord-Europe.

\section{REFERENCES}

Belbin, R.M., 2010. Management Teams. Taylor \& Francis.

Bodily, R., Verbert, K., 2017. Review of Research on Student-Facing Learning Analytics Dashboards and Educational Recommender Systems. IEEE Transactions on Learning Technologies 10(4), 405-418.

Bouchet, F. 2009. Characterization of conversational activities in a corpus of assistance requests. Proc. of the European Summer School for Logic, Language and Information (ESSLLI). pp. 40-50.

Dabbebi, I. et al, 2019. User Centered Approach for Learning analytics Dashboard Generation. CSEDU 2019.

Goldman, S. et al, 2019. Technology-mediated teacher-researcher collaborations. CSCL 2019.

Ifenthaler, D. and Seel, N., 2005. The measurement of change: learning-dependent progression of mental models. Technology, instruction, cognition and learning, vol. 2, no. 4, pp. 317-336.

Jeong, H. and Hmelo-Silver, C.E., 2016. Seven Affordances of Computer-Supported Collaborative Learning: How to Support Collaborative Learning? How Can Technologies Help? Educational Psychologist, 51:2, 247-265.

Jivet, I. et al, 2017. Awareness Is Not Enough: Pitfalls of Learning Analytics Dashboards in the Educational Practice. In Data Driven Approaches in Digital Education. pp. 82-96. Springer International Publishing, Cham.

Lucero, A. et al, 2016. Designing with Cards. In Markopoulos, P., Martens, J.B., Malins, J., Coninx, K., Liapis, A. (eds.) Collaboration in Creative Design: Methods and Tools, pp. 75-95. Springer.

McNair, L. D. et al, 2010. Towards a Pedagogy of Relational Space and Trust: Analyzing Distributed Collaboration Using Discourse and Speech Act Analysis. IEEE Transactions on Professional Communication, 53(3), 233-248.

Prieto Alvarez, C.G. et al, 2020. LA-DECK: A Card-Based Learning Analytics Co-Design Tool. In Proc. of the $10^{\text {th }}$ International Conference on Learning Analytics and Knowledge. Frankfurt.

Roberts, L.D. et al, 2017. Give me a Customizable Dashboard: Personalized Learning Analytics Dashboards in Higher Education. Technology, Knowledge and Learning 22(3), 317-333.

Roy, R. and Warren, J. P., 2019. Card-based design tools: A review and analysis of 155 card decks for designers and designing. Design Studies, 63, 125-154.

Ruiz, A. et al, 2018. Participatory design method: Co-Creating user interfaces for an educational interactive system. In Proceedings of the XIX International Conference on human computer interaction. pp. 1,8. ACM.

Sanders, E., 2002. From user-centered to participatory design approaches. In Design and the Social Sciences: Making Connections., pp. 1-7. CRC Press.

Schneider, B. et al, 2011. "Benefits of a Tangible Interface for Collaborative Learning and Interaction," in IEEE Transactions on Learning Technologies, vol. 4, no. 3, pp. 222-232.

Schwendimann, B.A. et al, 2017: Perceiving Learning at a Glance: A Systematic Literature Review of Learning Dashboard Research. IEEE Transactions on Learning Technologies 10(1), 30-41.

Tan, J.P.L. et al, 2017. Learner Dashboards a Double-Edged Sword? Students' Sense-Making of a Collaborative Critical Reading and Learning Analytics Environment for Fostering 21 st Century Literacies. Journal of Learning Analytics.

Teasley, S.D., 2017. Student Facing Dashboards: One Size Fits All? Technology, Knowledge and Learning. 384.

Verbert, K. et al, 2014. Learning dashboards: an overview and future research opportunities. Personal and Ubiquitous Computing 18(6), 1499-1514. 